\title{
Developing critical thinking skills by students through active methods of the study of literature
}

\author{
Svitlana Kovpik* \\ Kryvyi Rih State Pedagogical University, The Department of the Ukrainian and World Literatures, Kryvyi Rih, 50086, Ukraine
}

\begin{abstract}
The paper deals with ways of developing critical thinking by means of literary works. It represents a number of analytical, searching, and cognitive tools aimed at activating thinking operations in the process of reading and interpreting fiction texts. It also focuses on the active methods of studying literary words (event analysis, fishbone structures, socionist analysis) which develop student critical thinking. The results of the research have proved that modern openness of literary education allows diversifying the ways and tools of studying linguistic and fiction "fabric" of the literary text.
\end{abstract}

\section{Introduction. Analysis of recent research}

Nowadays the methods of teaching the Ukrainian literature represent original and genuinely new ways of studying fiction works. Currently, philology teachers remark that students merely lose interest to reading literary works. Consequently such a tendency greatly affects the quality of their literary education. Therefore, the primary task of a teacher is to encourage modern students to read fiction texts. It is noted that at present students are inclined to interpret rather than analyze the literary work at the lesson. That is why there is a constant need to develop student analytical thinking skills while studying works of fiction.

Taking into account the fact that cognitive study of a literary work is carried out through its systematic, complex analysis (investigation) as well as motivated and purposeful interpretation (explanation), it should be mentioned that these processes are interrelated, but should not be observed as identical ones. They share a similar survey subject, it is a piece of fiction text, in particular. However, the subjects of study in these processes are significantly different. The subject of analysis focuses on the work of fiction which is considered as a whole for the sole purpose, while the subject of interpretation comprises the content of the literary work including all its meanings and senses.

It is well known that the purpose of analyzing the fiction text is the process of scientific cognition, splitting and evaluating the text "fabric", whereas the purpose of interpretation is interpreting and rendering the text content for better recipient (addressee) understanding. Hence, the task of an analyst is to study the literary work as an art, aesthetic, social system, through all consciousness levels in terms of all possible contexts and intertexts. The interpreter task is to help the recipient (addressee) understand the author's intention, content and meaning of the text. The analysis is carried out by means of literary criticism categories and regardless of the availability of judgments and conclusions. The interpreter takes into account the purpose of particular interpreting, the age and the intellectual level of the addressee, etc. These processes are different in the way of priority ranking and cognition scope: the analysis precedes the interpretation; the interpretation of the literary work is impossible without its previous analysis, but text cognition is not limited to its interpretation. Moreover, it should be noted that there is a difference at the level of their principles: the analysis of a fiction work is carried out on exact scientific understanding, while the interpretation is very often implemented on the basis of artistic taste and extra-literary factors. There are also some variations in the methods, ways, types and levels of analytical and interpretation procedures.

Reviews of recent research papers and surveys over the last decade clearly show that even guidance counselors intensify their efforts to solve an important problem i.e. "the adaptation of the most interesting and efficient forms for traditional and non-traditional ways of fiction work analysis at school" [1].

The World Economic Forum has stated that critical thinking is among the top three competencies for a young person in 2020. The above mentioned list also includes "problem solving skills" and "ability to communicate", which are formed by means of special methods at the literature lessons.

The human thinking process requires its constant training and improvement during his/her conscious life. Every person has a unique ability of thinking critically. Critical thinking is an exceptional process that combines a number of important thinking operations as following: analysis, synthesis, justification of evaluation, information summarizing. The development of critical thinking provides the improvement of person's skills to perceive the situation in the global and broad-scale way,

\footnotetext{
* Corresponding author: kovpiks@ukr.net
} 
penetrating into the causes or alternatives of various phenomena, processes, etc. The uniqueness of critical thinking lies in the fact that a person develops specific skills to make balanced decisions. Scientists have already confirmed that this type of thinking is fundamentally different from creative, and intuitive types.

The development of critical thinking is not only an educational trend but also a social tendency. O. Pometun reasonably points out that critical thinking is "a human quality, the trait of his/her personality which is manifested not only due to the perception of information. This is a trait that manifests itself in the daily life, as we make many choices every day, and the more meaningful these choices are, the more developed critical thinking is" [1].

O. Slonovska in her research "Critical thinking fashion chips or effective tools in training and knowledge obtaining by pupils at the humanity lessons?" ponders over the idea of using the term "critical thinking" in school practice "as the synonym of a wellknown clear phrase "searching of literary work gist", based on a careful analysis of a particular literary work, character, clash, problem discussion through debating or chain way logical inferences. Obviously such systematic practice gives opportunities to achieve appropriate results and, above all, provide not intrusive and forced, but rather active, interesting and successful learning process" [2]. Views of O. Slonovska on functions of critical thinking are based on the need to develop the ability to analyze texts of fiction works. While analyzing Ukrainian literature texts at the lesson students learn to make logical conclusions, to give unbiased evaluation of character actions and behaviour. We share the opinion of O. Slonovska that critical thinking should be developed in every possible way among senior students, as it provides logical thinking development and psychology knowledge accumulation. Nowadays, critical thinking is an important skill of a modern person.

The purpose of the article is to reveal functional peculiarities of new active interdisciplinary methods of fiction studying, which are aimed at developing critical thinking among students.

\section{Presentation of the main research material}

It should be mentioned that the work of fiction is a result of unique creative thinking; therefore, it is very important for students at the literature lessons to analyze thoroughly and critically the actions, behaviour and the way of thinking of characters, giving them proper evaluation. The critical thinking complex includes a number of important mental processes: analyzing, comparing, synthesizing, hypothesizing, making assumptions, finding alternatives, making decisions. Critical thinking functions are to develop student's curiosity, establish cause-and-effect relationships between certain phenomena and processes, and form personal opinions. It also comprises the absence of mistake making fears, student readiness to dispute generally accepted truth, and logically comprehend important components of literary works.

Focusing on the development of student critical thinking, the teacher should consider the following steps in the structure of the literature lesson:

- the problem perception (this stage switches students on the problem, excites and provokes them to think, appealing to their previous knowledge. In terms of this phase, as well as during the whole lesson, it is important that the teacher speaks as little as possible and enables students to express their thoughts);

- the problem comprehension (this stage shows that students are entirely involved in the process of problem solving. It should be mentioned that the method of marking reading or INSERT means is of great use at this stage. This method allows students personally to determine already known information, to distinguish fundamentally new facts, to make notes indicating another way of thinking, to search for a better solution. It is important that the teacher puts series of free-answer questions rather than closed ones connected with the text. The teacher should not be afraid of free-answer questions, as they provide the development of student critical thinking);

- assessment or reflection (this stage is based on the consolidation of received information and new knowledge, restructuring ideas according to the new information, exchanging opinions with classmates about ways of problem solving).

As an instance, let us present a model lesson which applies the technology of critical thinking. It relies directly on the analysis of fiction works. At the beginning of the lesson, the teacher addresses to students, using the following motto of the critical thinking lesson: "You ask - you think!". This motto guides students in the way that putting the question stimulates their thinking process.

At the stage of comprehending the problem, firstly, the teacher invites students to identify the information that helps to reveal the meaning of the text. Among them there are the following: information about the history of work writing, the reasons for the involvement of cultural codes into the structure of the literary text.

Using the method of marking reading or INSERT suggests students to write down priori information, and separately make notes about the new facts. Afterwards they start to consider the ways of solving the conflict presented by the writer, and actively discuss it. Then students mark the text in such a way that the marks correspond to the following answers: "I knew it", "I knew but forgot", "New for me", "I thought different", "I want to know more".

Marking of the text can be submitted in the way of a table. The sample text marking is shown below (table 1).

Table 1. Marking of the text.

\begin{tabular}{|c|c|c|c|c|c|}
\hline $\begin{array}{c}\text { I knew } \\
\text { it }\end{array}$ & $\begin{array}{c}\text { knew but } \\
\text { forgot }\end{array}$ & $\begin{array}{c}\text { New } \\
\text { for me }\end{array}$ & $\begin{array}{c}\text { I thought } \\
\text { different }\end{array}$ & $\begin{array}{c}\text { I want to } \\
\text { know more }\end{array}$ & $\begin{array}{c}\text { My own } \\
\text { ideas }\end{array}$ \\
\hline 1 & 2 & 3 & 4 & 5 & 6 \\
\hline
\end{tabular}


At the assessment and reflection stage, students express their thoughts based on summarizing information, which they have received, consolidating new knowledge, demonstrating how their knowledge has changed as new information has been acquired. Students share ideas about the ways of problem solving. Here it is necessary to adjust students' opinions of solving the problem to the way chosen by the writer. That is why nowadays it is very important to use critical thinking methods while studying the works of the Ukrainian literature, as they provide a brand new way of reading classics.

At this stage, fishbone technology can be applied. It allows students to answer a number of questions: "Why did the writer create the conflict in such a way?"; "Why did he focus the reader's attention on this or that event?"; "What is the essence of the writer's strategy?" Fishbone technology (fish skeleton) provides a fish-tail pattern. The determined problem is considered to be the head of the fish, the upper bones are the causes; the lower bones represent illustrative examples (facts and arguments). The tail gives the answer to the question. The author of this technology is Japanese professor Kauro Ishikawa, who has developed this technology for structural analysis of cause-and-effect relationships [3, 4].

Students write down this scheme using keywords or short phrases. While making the scheme students gradually find the answer to the question, which turns to be the tail of the fish. This scheme promotes better information memorizing, improves search and cognitive abilities, and develops logics and conclusion justifying skills.

Fishbone technology encourages students for groups work, develops critical thinking, visualizes the links between the cause and the effect, and ranks the facts in order of their importance.

Hence, we believe that the technology of critical thinking today should be actively implemented into the senior school practice of teaching the Ukrainian literature, because this technology has a number of important functions that contribute to the development of important thinking resources of modern youth:

- the independence of critical thinking makes to obtain ready knowledge not from textbooks, but to spend time on its acquiring from other sources;

- the process of critical thinking considers information as the starting point and not the destination one;

- critical thinking allows setting problems on the basis of student life experience;

- it carries out self-esteem of student activity;

- critical thinking develops skills of appropriate decision making;

- it helps to express thoughts in logical way and give convincing arguments.

It should be noted that the active methods of event analysis also deserve certain attention. These methods manifest a peculiar way of analytical and progressive studying the dynamics and the development of both separate events and sequence plot twists. This technology appeared in the $1960 \mathrm{~s}$, but today it has gained popularity mainly in political studies, less in conflictology and sociology. This method is primarily applied to investigate the development of purely military-political and strong socio-political confrontations, mass disruptions and it monitors the development of international events during certain periods. The following analysis is carried out according to a fairly established scheme: the subject-initiator of the event (who), the determinant of its development or the development of the event series as a complete "plot" of events.

Applying this technology in terms of literary studies is relevant, especially while studying events and event series in drama historical works.

At present in the Ukrainian literary criticism there is research dedicated to understanding the essence of specific events. The monograph "An Event in the Artistic System of Contemporary Ukrainian Prose: Morphology, Semiotics, Reception" (2010) by T. Grebeniuk confirms this statement. The researcher emphasizes in one of her study ("Event category in the receptive-communicative paradigm of the analysis of a literary work") that the event makes a basic, starting concept in distinguishing the literary genres, with the precise defining various literary terms, such as: "plot", "motive", "genre", "chronotope", "narrative", etc. She suggests that "because of its apparent empiricism and routine, this category is often perceived as extrascientific, not worthy of professional analysis, and only in single theoretical works there are some attempts to represent it as a specific element of the literary work system" [5].

That means that T. Grebeniuk tries to comprehend the dynamics of events through the literary studies discourse, which is caused by paradigm shifts of scientific thinking, although the researcher does not specifically focus on the analysis of the event series in the literary work. Yu. Lotman gave his brief definition of a phenomenon called "event": "The text event represents the character who transfers the border of the semantic field" [6]. At the same time, the scientist emphasizes that the event is exceptional staying at the background of other components of macropoetics in the literary work, and it requires special study.

W. Schmidt interprets the event as the sequence of initial situations changing one another, whether external or internal and related to the character. In addition, the researcher defines the category "literary work eventuality" as a gradational peculiarity of events. The scientist identifies several conditions that should correspond to "narrative eventuality", which is marked by "factuality" (or reality), that is the obligatory connection between the events and their results [7].

"Narrative eventuality" has the following five major gradation relevant changes: eventuality increases if the change that has occurred is essential for this world; "unpredictability of an event", which indicates the increase of occasional properties; "consecutivity" shows that eventuality increases if changes have a significant impact on the process of thinking and consciousness of the character on the way of his subsequent actions and behaviour; "irreversibility" represents that the changes turn out to be definitely irreversible; "uniqueness" emphasizes that the changes can not develop otherwise. 
Modern literary studies manifest several approaches to event and eventuality of literature activity comprehesion. Firstly, they are considered as "unfolding the plot in a fiction work that influences on the development of a story line, clashes, conflicts, the behavior of characters. It can be an action, an act, a chance. At the same time it is interpreted as an existent and one of the fundamental components in the story. Secondly, "plot event" is determined as the transfer of the character, "internal or external", that is crossing "the border, separating parts or spheres of the described space and the moment of literary time associated with the probable implementation of the planned events or vice versa its failure" [8].

In addition, N. Tamarchenko defines the concept "plot situation" as inseparable manifestation of time and space conditions. Moreover, it is stated that the transition from one situation to another is possible only in terms of replacing or transforming the character's conditions, changing his personal activity or shifting "activity" and "effectiveness" of external circumstances.

In drama works the event-creating situation helps to determine the relation between the counteracting forces, characterize the coincidence of conditions and circumstances, relationships and behavior of the characters. It also emphasizes the moment of conflict resolution.

It is supposed that the event situation of drama works can be represented by means of a number of different factors or a single replica of a character, who does not seem to generate an event, but noticeably prepare the specified situation, which can cause the event or even transform into it. If the plot of a play is the entire system of character clashes and intertwining of the story lines, then the main plot of the play is nothing but the system of events in its artistic reality. It forms the basis of its content, determines the essence and stages of a separate conflict or conflict systems. It may even make changes to its characters, etc.

It should be mentioned that playwrights P. Cornell and N. Boileau were the first who widely introduced the concepts of "event", "event development", "event exacerbation" in drama works, considering any fact, phenomenon or process of private or social life of a character as crucial and significant. Only then such situations can be determined and called events. Till the middle of the nineteenth century drama works showed concentric and holistic plots, in which all the actions of characters were subordinated to "the unity of actions", connected by one conflict, and the eventual chains were short and predictable.

The significant "liberation" of the processes and elements of micro- and macropoetics and composing poetics from these canons provided emergence of new poetic peculiarities and combinations of a play. It caused different types of transferring and reconstructing the time and space. It gave the way to brand new concentric systems of conflicts, and consequently to the accumulation or reducing of cause and effect relationships between the actions of characters and between the events of fiction works.
Certain events and event sequences of literary works start to be filled with new content, take new forms and formats, acquire new specific features and functions: from traditional and predictable features of plot dynamics to virtual-phantasmagoric and purely mystical shocks and shifts in the consciousness of individual characters, from fights and conflicts between characters to confrontations between ethnic groups and nations. Since the events and the event sequences, in particular, create peculiar psychofields, they not only allow the characters to reveal their nature to the recipient, but also determine the extent of their self-expression, requiring them to manifest their attitude to both certain events and event sequences. Moreover they can even become "an actant" (fr. actant - action move) events, that is why such play characters are typically "the engines" of event unfolding in literary works.

It should be also mentioned that the amount of events does not always depend on a number of participants, as it is often on contrary. The power and influence of the character can ultimately determine the following: the event in the life of one person may become the event of the whole nation and society, or vice versa, the event of the universal scale can change the life of one person. It is most likely that everything is settled due to the interdependence and interconnection of characters, people and events, the degree of intertwining of their goals and consequences.

The levels of conscious struggle and the nature of events and their participants, motives and conditions of events are not always the same. In this case much and / or even everything depends on the level of character consciousness, the level of the problem according to which the events or event sequences are completed, and the essence of social or natural events, etc.

Furthermore, literary critics divide the events of works into "setting" (events that give rise to fights, conflicts and confrontations), "major" (events during which these conflicts or confrontations are solved). However, not every single component of an event sequences is an equal and valuable part of its "throughgoing action", which can even begin with an insignificant event and be interrupted by several events. The ultimate event takes an extraordinary shape when it reveals resolving the crucial conflict in the end of the work.

In addition, acting as a plot, climax, and resolving in the play, events change not only the general nature of the "event development", but also the whole struggle of the characters, the general line of their behavior, being "catalyst" or "inhibitor" of the overall plot development. Probably this is the reason why some researchers consider event sequences to be the coincidence of circumstances that escalate into a certain situation, etc. Only when an event or event sequences become obsolete both in time and space, a significant retardation of events starts or the events of the work completely come to end.

As a result the event sequences of a literary work simultaneously make up its full structure, its main core (plot), and such a "turning point" of its development which may not be studied by the event analysis, but may 
be the main manifestation of genre-defining pathos, the ideological and aesthetic essence of the play.

It should be emphasized that certain events and event sequences in a drama play can also have double spatial and ambiguous temporal characteristics.

The main tasks of the event analysis method in literature lessons are the following:

- to teach students to explore the essence of each event and event sequences of the whole literary work, paying attention to their functions and the conditions of their development;

- to form the skills of analyzing all realistic and virtual events and characteristics that are in fact the main causes of character thinking and struggle, their emotions, moods, states and feelings, actions, and behavior, fight and lifestyle;

- to identify the main issues of the work that break the settled way of life of the character, events and event sequences, which attract to the work and rise the special interest of the recipients.

The series of analytical actions in accordance with the method of event analysis of a literary work include such steps:

1) determining the initiator of the event (character, forces of nature, phenomena);

2) identifying the actant character of the event (that is the one who moves, starts, aggravates the problem);

3) measuring the event magnitude in the work by a number of participants (micro-event (two participants) and macro-event (over two participants));

4) defying the influence of the event (an event from the life of one person, an event from the life of a nation, society);

5) defining the type of event: event-gesture, eventreplica, event-facial expression, event-action, eventword, event-case, event-sit.

Lately, most emoji researchers are convinced that these characters have great hypertext potential. For instance, there have been attempts to translate the text of the novel "Moby Dick" by Herman Melville's using the appropriate emoji, called "Emoji Dick".

Today, emoji is not only a linguistic tool, but also a psycho-physiognomic means. By modeling this or that facial expression of an emoji, the author shows it the emotion that matches his / her level of sensuality. The emoji face performs an informative function; it tells the interlocutor the emoji author's response to the text which greatly differentiates written communication.

Therefore, by making the sense of poetry through a self-designed emoji body in Emoji-Maker, students have the opportunity to expand the range of emotions, moods and experiences that arise in the process of reading poetry and especially while its interpreting. Emoji face expression is a students' creative approach to understanding the essence of prose and poetry. After all, all human feelings are expressed not in words but facial expressions. So we offer emoji modeling technology that reproduces the artistic meaning of poetry.

Present day psychology, sociology and literary critics research shows the interest to the results of socionic achievements. Socionics is a new branch of knowledge that, since about 1970-ies predicts interpersonal relationships, helps to model relationships between representatives of different social groups, social institutions, and as a result, it allows the most effective implementation of personality socialization in the modern world.

Nowadays, the socionists have identified 16 types of personality, which they call sociotypes. In socionics, the sociotype is formed on the basis of knowledge about the psychotype and is connected with the social level of a person, the type and kind of his / her occupation, profession, and the level of intellectual development. Recently, pedagogy has become a new area of socionics in terms of team compatibility studying, training, family counseling etc.

At present, the main task of socialization at school is the process of thorough transmitting all the necessary knowledge and skills to a student for his / her successful entry into the society, as later students have to fulfill certain social roles. The socialization of modern schoolchildren is a key to their rapid adaptation in the society.

Sociologists distinguish the main mechanisms of socialization such as imitation, attachment to one of the family members, identification, competition awareness, etc. The difficulties of socialization are related to three main circumstances: the difference between the high levels of demands (the desire to become a hero, be famous, stand out) and a low social status, which is associated with certain age characteristics, as well as the divergence of an old style of paternity, which is oriented to the idea that for a mother her son or daughter always remains a child; new potential abilities of teenagers, made up by their psychophysiological adulthood; contradictions between the increased orientation towards their independence and dependence, which are enforced by the opinions and behavior of age-mates.

Socionists define several sociotypes. The first one is an intuitive-logical extrovert (inventors, innovators, producers of new ideas, thoughts etc.). Foreign fiction works depict this sociotype in the characters of Jacques Paganel (J. Verne "Children of Captain Grant"), Alice (L. Carroll "Alice in Wonderland"). Such people are marked by some awkwardness, absent-mindedness, but they are hardworking and good-natured, sincere and open, simple and creative, they are true friends who you can always rely on.

The next sensory-ethical introvert type includes mediators, peace-makers, and executors of someone's orders. Foreign fiction characters of this type are a soldier Schweik (J. Hasek), Sancho Panza and others. In the Ukrainian literature, it is illustrated by Nazar Stodolia's cobrother, Mykola (I. Kotliarevskyi "Natalka Poltavka"). Such characters stand out in society due to their desire to reconcile and cement relationships within the community; they act as intermediaries between the two opposing parties.

The following sociotype is an ethos-sensory lifelong enthusiast, optimist, promoter, salesman, salesman, manager implemented in such characters as: Moskalmagician, Mykola (I. Kotliarevskyi "Natalka Poltavka"), Santa Panko (Ostap Vyshnia "Som") etc. 
The logic-intuitive introvert is represented by a fair analyst who is slow-moving, thoughtful, and difficult to enter the society. This type of personality can be noticed in the character of Mykhailo (M. Stelmach "Geese swans fly").

The intuitive extrovert is a teacher, mentor, educator, who constantly tries to be the first and it is manifested by Uncle Sebastian (M. Stelmakh "Geese swans fly"), Maurice Gerald (M. Reid "The Headless horse rider"), Margarita (M. Bulgakov "The Master and Margarita").

The logic-sensory introvert is an inspector, controller, and supervisor. This sociotype is represented in the foreign literature by the Constant Tin Soldier (H.-Cr. Andersen "The Constant Tin Soldier"), Malvina (A. Tolstoy "The Golden Key").

The intuitively-ethical introvert is a dreamer, a direct and desperate romantic, living on the principle of "the river flowed, flows and will flow". These are the people who as much as possible disconnect themselves from problems and well shown by the character of Ivan (P. Zagrebelnyi "B-en").

The sensory ethical extrovert is a patron. Artistic images in literature are the following: Lolita (V. Nabokov "Lolita"), Puss in Boots (Sh. Perot "Puss in Boots"). An important role in the study of sociotypes is given to the knowledge of social setting.

Thus, the socionic setting of a sociotype for a certain activity reveals an individual natural inclination to a particular profession, and the knowledge of his / her psychological type makes it possible to choose a proper profession, i.e. "related work". Each professional environment, in turn, requires a person to obtain certain psychological traits.

The information model of each psychotype allows determining the relations between the characters and identifying who will get along well and who will be constantly engaged in conflict relations. It is a crucial point for adaptation and it is the basis of the theory of interpersonal relations. The knowledge of the differences and similarities of psychic functions within the information model of the psyche allows accurately determining how the relationship between different psychotypes will develop. Different squares determine different relationships between individuals. Moreover, it can be useful for family planning and just in friendships matters. It is worth mentioning that a mental function is an ability of a person with particular skills to understand the information flow aspects. It is clear that mental functions are as numerous as the aspects; each aspect of the information flow corresponds to a certain mental function.

Practical psychology, mainly due to the attempts of psychologists K. Leonhard, A. Lichko, formed the idea of personality psychotypes, expressed through accentuation of characters, and developed corresponding typologies. It was noticed that these combinations of character traits are not countless, but they can be grouped into ten categories.

Psychologists emphasized that the character may be more or less expressed. The intensity of the character manifestation is revealed in terms of "norm", "accentuation", "pathology" or "psychopathia".
At the literature lessons the following model of determining the essence of each character psychotype to define their social compatibility is presented to students: the basic function identifies a person's occupation; the creative function focuses on the fact how a person implements his / her work; the role function shows person's role in a specific situation; the pain function covers complexes and vulnerabilities; the suggestive function allows a person to be influenced by someone; the activation function reveals the skills of selfrealization; the supervisor function is responsible for receiving and processing information; the demonstrative function shows a person in action.

Therefore, knowledge of typical character traits and behaviors will help students in the future to understand a particular person, to know his / her unique personality. And this contributes to the rational use of human resources, reducing the level of conflict in small social groups and in society. It also provides the high level of self-realization of each person in those areas of life that are the most inherent.

Since socialization is an awareness of individual social experience, social connections, relationships; the lessons of the Ukrainian Literature, where students study sociotypes, are an important platform for students experience development. Using this experience, the students can meet new social requirements, and get ready for the transition to new social conditions. Psychologists and sociologists argue that individual socialization is a lifelong process, and the change of certain social principles or attitudes depends on changes in ideology, values and attitudes.

For better understanding of a character behavior model, students are offered the following algorithm of mental operations: to analyze intentions and plans of an action that precedes the action of the character; to identify the essence of the character's beliefs; to analyze the reactions, emotions of a character in terms of the words, and actions of other characters; to consider the reaction of the social environment to the behavior of a character; to determine how fast and why a character changes social settings; to understand how much the change in social attitudes influences his / her behavior in the future.

Consequently, lessons of the Ukrainian Literature, using the method of socionist analysis of literary works, help to assist student integration of into the society or various types of communities (groups, social institutions, and social organizations) due to studying the elements of culture, social norms and values that form socially significant personality traits. Lessons of the Ukrainian Literature make the process of socializing easy for students, and teach them to communicate with representatives of different social groups.

Taking into account that socialization is a long and multiaction process, it is worthwhile to adjust students to the fact that modern society is frequently evolving, and its structure is changing. At the same time, a person's life, age, attitudes, preferences, habits, rules of behavior, statuses and roles are constantly changing the life as well. By means of socialization, people fulfill their needs, opportunities and talents; establish relationships 
with other society members, groups, social institutions, organizations, which gives them more confidence.

\section{Conclusions}

Thus, the active methods of studying literary works proposed in the paper are clearly oriented to the development of personal critical thinking. Modern openness of literary education involves into the process of studying and analyzing the texts of fiction various psychology, conflictology, sociology tools, which contribute to the diversity of active working forms at the Literature lessons, and increase the interest to literature study.

We believe that active methods and technologies will be effective if there is their systematic usage. In our opinion, the following methods and techniques are active and productive: event analysis, INSERT reception, socionics character analysis of fiction works.

The diversification of using active methods at the literature lessons is a promising sphere for further scientific research, which will allow developing the system of modern methods of complex literary work studying in the future.

\section{References}

1. O. Pometun, Osnovy krytychnoho myslennia (Fundamentals of Critical Thinking). (Bohdan, Ternopil, 2010)

2. O. Slonovska, Horizons. 2, 29-30 (2013)

3. K. Ishikawa, The Japanese Way 13, 44-45 (1985)

4. K. Ishikawa, Guide to Quality Control (Asian Productivity Organization, Tokyo, 1976)

5. T. Hrebeniuk, Podiia $v$ khudozhnii systemi suchasnoi ukrainskoi prozy: morfolohiia, semiotyka, retseptsiia (Event in the artistic system of contemporary Ukrainian prose: morphology, semiotics, reception). (Prosvita, Zaporizhia, 2010)

6. Yu. Lotman, Structura khudozhestvennogo teksta (Structure of the artistic text). (Iskusstvo, Moskva, 1970)

7. V. Schmid, Narratologiya (Narratology). (Slavyanskie kulturyi, Moskva, 2003)

8. Yu. Kovaliv, Literaturoznavcha entsyklopediia (Literary Encyclopedia). (Akademiia, Kyiv, 2007) 